\title{
CAN LOW COST ROAD ENGINEERING MEASURES COMBAT DRIVER FATIGUE? A DRIVING SIMULATOR INVESTIGATION
}

\author{
A. Hamish Jamson and Natasha Merat \\ Institute for Transport Studies \\ University of Leeds, U.K. \\ Email: a.h.jamson@its.leeds.ac.uk
}

\begin{abstract}
Summary: Driver fatigue is a major cause of road accidents, accounting for over $20 \%$ of serious accidents on motorways and monotonous roads in the U.K. This study investigated the potential for low-cost, road-based, engineering measures to act as alerting features in an otherwise monotonous driving environment and hence combat fatigue. Thirty-three drivers took part in the driving simulator study. There was some evidence of an alerting effect provided to drivers by all three of the treatments tested: chevron road-surface markings, transversecarriageway rumble strips and variable message signs. However, the alerting effect did appear to be relatively weak and potentially quite short-lived. Nevertheless, there may well be potential for any of the novel alerts to be deployed in the field in a known fatigue-related accident area.
\end{abstract}

\section{INTRODUCTION}

Driver fatigue is a well recognised threat to transport safety. Using survey data, Maycock (1997) estimated that fatigue is a contributory factor in $20 \%$ of U.K. motorway accidents. Similarly, Horne and Reyner (1995) showed that fatigue could be implicated in $23 \%$ of accidents occurring on long stretches of monotonous motorway. In the U.S., the picture looks even bleaker. McCartt, Ribner, Pack and Hammer (1996) stated that on highways or expressways, $40 \%$ of all accidents are sleep-related, whilst Dinges (1995), in a review article, puts the $40 \%$ figure on the number of highways accident fatalities directly attributable to driver inattention though fatigue.

As the driver is perpetually the root cause of fatigue-related accidents, much of the research has focussed on how and why the onset of fatigue is so disruptive to safe control of a road vehicle. Driving is often considered to be a vigilance task. Increased tiredness influences the ability of a driver to maintain vigilance, hence adversely affecting driver performance. This impaired performance contributes significantly to accident risk (Sagberg, 1999).

The link between impairment through fatigue and risk shows itself clearly in accident statistics. For example, fatigue accidents tend to occur in regions of long, tedious and repetitive scenery (Horne and Reyner, 1995). Furthermore, fatigue-impaired performance is also related to time of day and to disruptions in an individual's circadian rhythm (Benoit and Foret, 1988), one explanation as to why a significant proportion of sleep-related accidents occur during the early morning (2am-6am) and mid afternoon (2pm-4pm) (Pack, Pack, Rodgman, Cucchiara, Dinges and Schwab, 1995). Whilst the fatigue-impairment-risk link is clear, perhaps most damningly, recent studies have shown that drivers are well able to recognise the onset of fatigue. However, they typically underestimate its impact, choosing to ignore their feelings of drowsiness and continue driving even when they become sleepy (Reyner and Horne, 1998). 
Some attempts have been made to combat fatigue using road-based engineering treatments that have a driver-alerting effect. Rumble strips, unevenness in the road surface, normally placed close to the edge line and centre line are commonly used throughout the U.K. highway network. Their purpose is to cause vibrations or noise when a wheel of the vehicle makes contact, hence alerting the distracted/sleepy driver about the imminent danger of a lane excursion. Studies have estimated that rumble strips can reduce fatigue-related accidents by between $15 \%$ and $40 \%$ (Mahoney, Porter and Donnell, 2003; Räsänen, 2005).

So, if the driver is the chief culprit behind fatigue-related accidents, due to an impairment that he/she recognises but chooses to ignore, and an external intervention can significantly raise driver alertness, can other such road engineering measures be similarly effective? This was the main aim of this study, funded by the U.K.'s Highways Agency, comparing three such engineering interventions:

- Chevron road-surface markings, situated every $40 \mathrm{~m}$, and currently used to help drivers maintain a safe following distance in motorway traffic.

- Transverse-carriageway rumble strips, currently used as a warning of impending changes to the roadway, e.g. on the approach to a village gateway.

- Variable message signs, carrying a warning message and giving the opportunity for a driver to engage in some cognitive activity to alleviate monotony by solving a simple mental arithmetic problem.

If effective, one or a combination of treatments could be deployed in a known "fatigue-related accident blackspot" (e.g. a long, straight, monotonous area of highway) and thus help avoid such accidents within the U.K.'s road network.

\section{METHOD}

\section{University of Leeds Driving Simulator}

The study was performed using the University of Leeds Driving Simulator (Figure 1). The simulator's vehicle cab is based around a 2005 Jaguar S-type, with all of its driver controls fully operational. A Seeing Machines faceLAB v4.5 eye-tracker is integrated within the cab, which itself is housed within a $4 \mathrm{~m}$ diameter, composite, spherical projection dome. The projection system that displays the visual information consists of eight channels, five forward and three rear
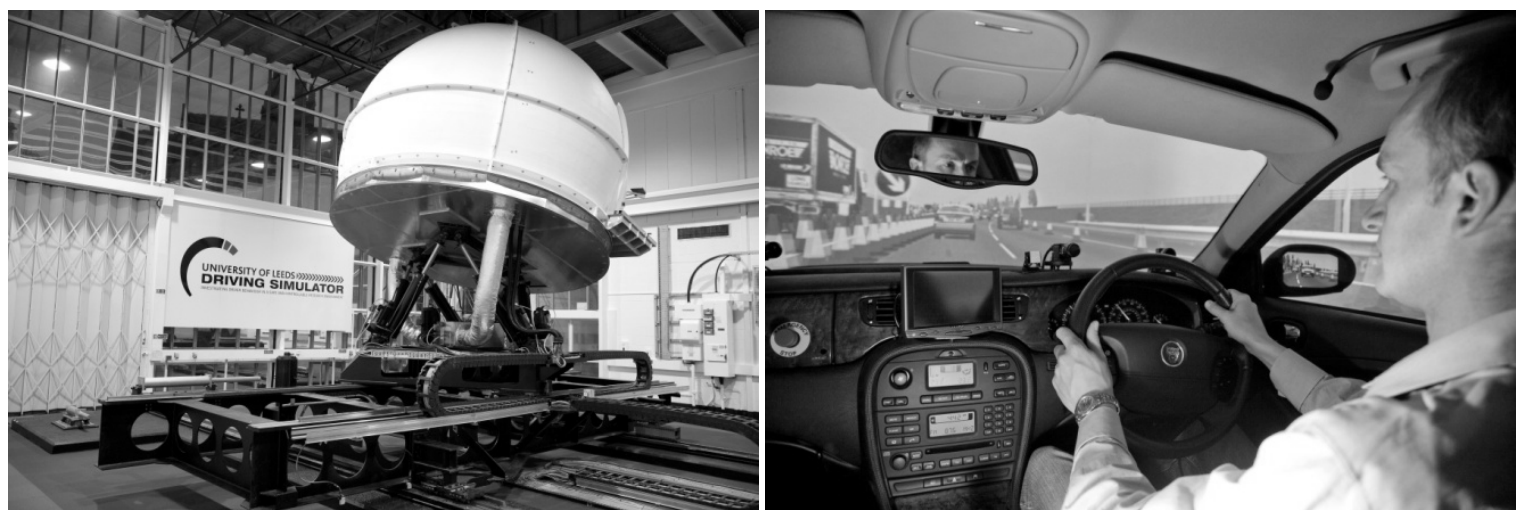

Figure 1. Exterior view and vehicle cab of the University of Leeds Driving Simulator 
views. The forward channels are edge-blended to provide a near seamless total horizontal field of view of $250^{\circ}$. The vertical field of view is $45^{\circ}$. The main rear channel $\left(40^{\circ}\right)$ is viewed through the vehicle's rear view mirror, whilst LCD panels are built in the Jaguar's wing mirrors to provide the two additional rear views.

The simulator incorporates an eight degree of freedom motion system. Lateral accelerations are simulated by sliding the whole vehicle cab and dome configuration along a railed gantry. Similarly, the whole gantry slides along tracks to create longitudinal acceleration cues. The $10 \mathrm{~m}$ long rails and tracks allow $5 \mathrm{~m}$ of effective travel in each direction. In addition, sustained cues are provided by a standard $2.5 \mathrm{t}$ payload, electrically-driven hexapod.

\section{Participants}

33 volunteers took part in the study, split into two groups. Previous research (e.g. Pack et al., 1995) has shown that young drivers (especially males) and shift-workers are more likely to be involved in sleep related traffic accidents. Hence, the first group was made up of young $(<35$ years old), male shift-workers $(\mathrm{N}=17)$. This group participated at the conclusion of an 8 -hour night-shift. The corresponding group $(\mathrm{N}=16)$ was made up from older male drivers ( $>45$ years). Both groups were randomly selected on the proviso that they had held a driving licence for at least three years and drove in excess of 3,000 miles per year.

\section{Experimental procedure}

Each participant drove the simulator in two separate sessions. The first session took place in the morning, after both groups of drivers had had a full night's sleep. First, all participants completed the Epworth Sleepiness Scale (Johns, 1991) to pre-screen for any chronic sleeprelated disorders (no evidence of such disorders existed within either group). Next, a single drive of around 30 minutes in duration was undertaken that allowed both a familiarisation of the simulator and an opportunity to collect baseline, non-fatigued, driving and eye-tracking data. The virtual driving scenario in the baseline drive consisted of a typical U.K. motorway and was $56 \mathrm{~km}$ (35 miles) in length. The virtual traffic was sparse (approx. 500 vehicles / per hour).

In the second session, drivers arrived in a "fatigued" state. For the older group, this was in the post-lunch dip period from $2 \mathrm{pm}-4 \mathrm{pm}$, whilst for the shift-worker group, the session began at $8 \mathrm{am}$, immediately after the conclusion of their night-shift. The session involved three drives, similar in duration and layout to the baseline drive, but each including one of the three engineering treatments. Each of the three treatments was $3 \mathrm{~km}$ (1.9 miles) in duration and located $48 \mathrm{~km}$ after the start of the drive, to allow 20-25 minutes of monotonous driving for fatigue to build up. The order in which participants experienced the treatments was counter-balanced. However, participant recruitment and time constraints conspired to leave neither group containing the desired multiple of six, and hence a fully balanced design was not achieved. 


\section{Treatments}

\section{Chevron markings}

In the U.K., chevron markings are painted onto the road surface of all three lanes at intervals of $40 \mathrm{~m}$ and are intended to remind drivers to keep a safe distance from the vehicle in front (Figure 2). Since these markings are already used in the U.K., it was hypothesised that chevrons may have supplementary benefit: their presence in a monotonous driving task may help to temporarily stimulate fatigued drivers. In the present study, chevrons were located at $40 \mathrm{~m}$ intervals throughout the $3 \mathrm{~km}$ treatment region.
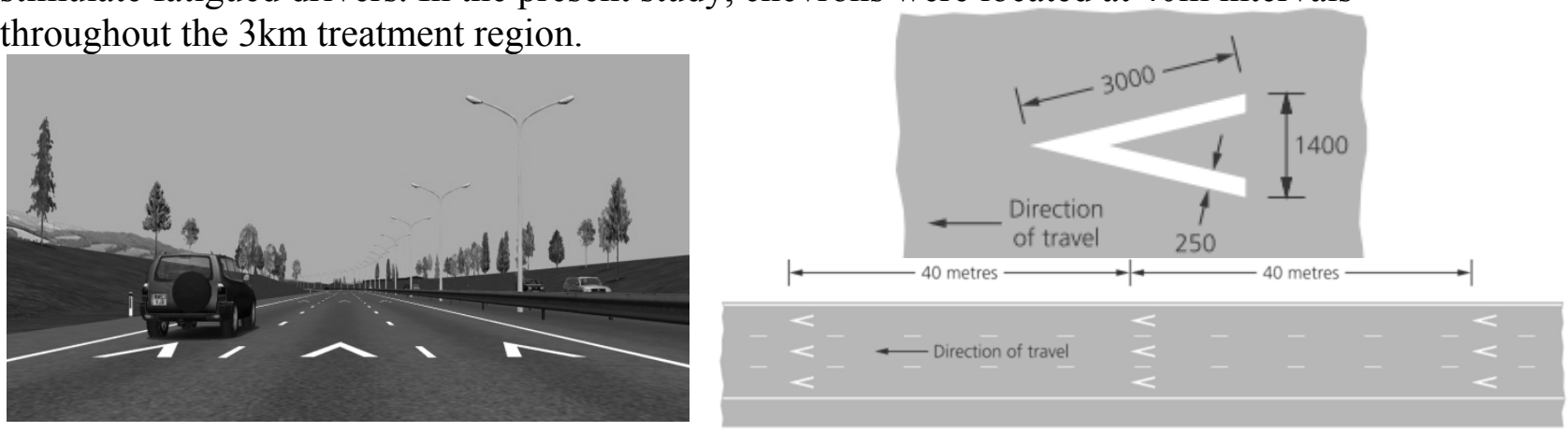

Figure 2. Chevron markings

\section{Transverse rumble strips}

Yellow transverse rumble strips are commonly used as a hazard warning, for example on the approach to a village gateway. Whilst not currently used in a motorway environment, it was hypothesised that the visual and tactile feedback associated with rumble strips (through the simulator's motion system) could also bring about a temporary alert to a fatigued driver. Rumble strips (Figure 3) were located at the start, middle and end of each $3 \mathrm{~km}$ treatment region.
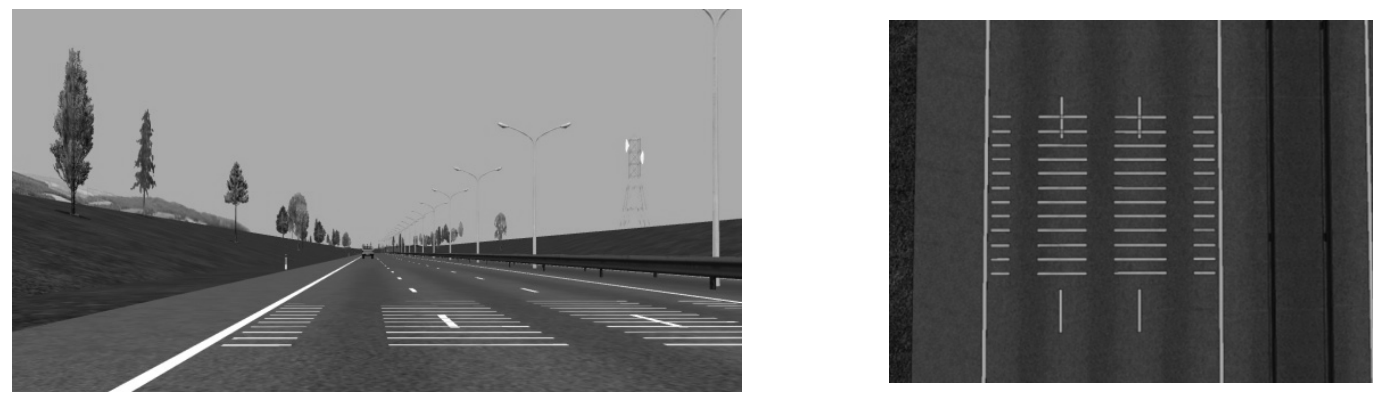

Figure 3. Rumble strips

Variable message signs

Variable Message Signs (VMS) normally supply drivers with up-to-date information regarding road and travel conditions. Within this study, three VMS were located over the $3 \mathrm{~km}$ treatment zone and displayed non-standard messages intended to alert a fatigued driver through an invitation to take part in some simple mental arithmetic. In the order that participants experienced them, the signs (Figure 4) read:

1. "TIREDNESS KILLS, ENGAGE YOUR MIND"

2. " $(3 \times 4 \times 5) \div 6=? ? "$

3. " $3 \times 4 \times 5) \div 6=10$, STAY ALERT" 

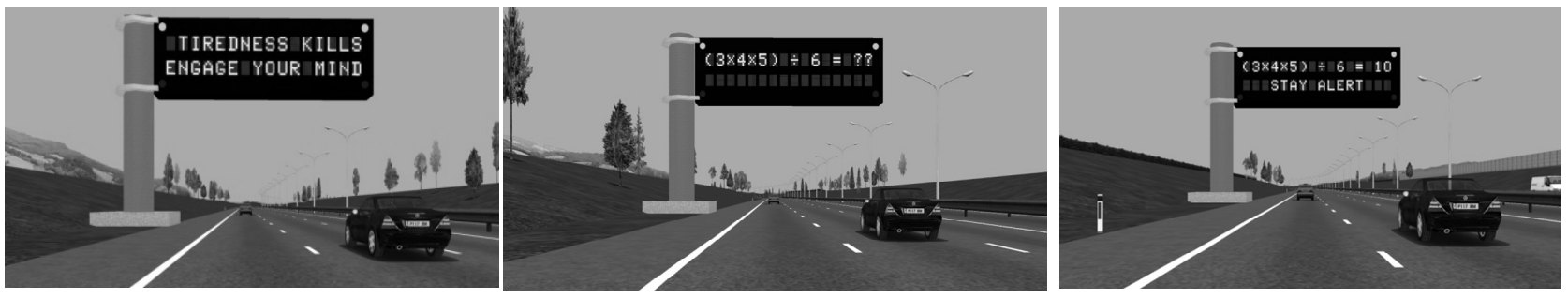

Figure 4. Variable message signs

\section{Dependent variables}

Several dependent variables of driver performance such as deviation in lane position, headway, time to line crossing were recorded, but only one is presented here: high frequency component of steering. The high frequency component of steering, normally associated with driving task demand, is defined as the ratio between the power of the high frequency component and of all steering activity. The magnitude of the high frequency band of steering wheel angle reflects steering corrections. However, this method aims at excluding the effect of open loop behaviour, only focussing on steering corrections. Increased corrections are commonly associated with more erratic steering performance in the face of some distraction (MacDonald and Hoffman, 1980). The distracter in this case is fatigue. Khardi and Vallet (1994) demonstrated that steering wheel reversals are a reliable indicator of sleepiness, with both the number and amplitude of these increasing with sleepiness, and correlating significantly with the amount of theta and alpha activity appearing in an individual's EEG.

In addition to this objective measures, driver drowsiness was be assessed using Percent Eye Closure or PERCLOS (Wierwille, Ellsworth, Wreggit, Fairbanks and Kirn, 1994). PERCLOS, is based on the eye closure of the subject, in particular the percentage of extended periods with practically closed eyes in a time window of fixed size. The method specifically discounts "regular" eye blinks which are excluded from the data. PERCLOS was recorded using the in-cab eye-tracker.

\section{RESULTS}

The first $45 \mathrm{~km}$ of a simulated drive was simply to allow the onset and build-up of fatigue within an individual driver. Results were compared in three main regions:

- before - $3 \mathrm{~km}$ region preceding an anti-fatigue treatment: $45 \mathrm{~km}-48 \mathrm{~km}$ into each drive.

- treatment - $3 \mathrm{~km}$ region of an anti-fatigue treatment: $48 \mathrm{~km}-51 \mathrm{~km}$ into each drive.

- after - $3 \mathrm{~km}$ region following an anti-fatigue treatment: $51 \mathrm{~km}-54 \mathrm{~km}$ into each drive.

\section{PERCLOS}

The first analysis undertaken was to assess the ability of the PERCLOS measure to discriminate between varying levels of driver fatigue. Hence, a two-factor repeated measures ANOVA was undertaken using data recorded from the 'before' region only and presented in Figure 5:

- within-subjects factor of drive (four levels: baseline, chevron, rumble and vms)

- between-subject factor of group (two levels: older and shift) 
There was a highly significant main effect of drive, $F(3,93)=19.3, \mathrm{p}<.0001$. Pairwise comparisons show that this effect was between the baseline drive and each of the 'fatigued' treatment drives (base-chevron, $\mathrm{p}<0.0001$; base-rumble, $\mathrm{p}<0.0001$; basevms, $\mathrm{p}<0.0001)$. There was no significant difference between the three treatment drives and so this measure clearly shows that drivers, as expected, are becoming more fatigued (showing significantly higher PERCLOS) from their baseline drive to their treatment drives.

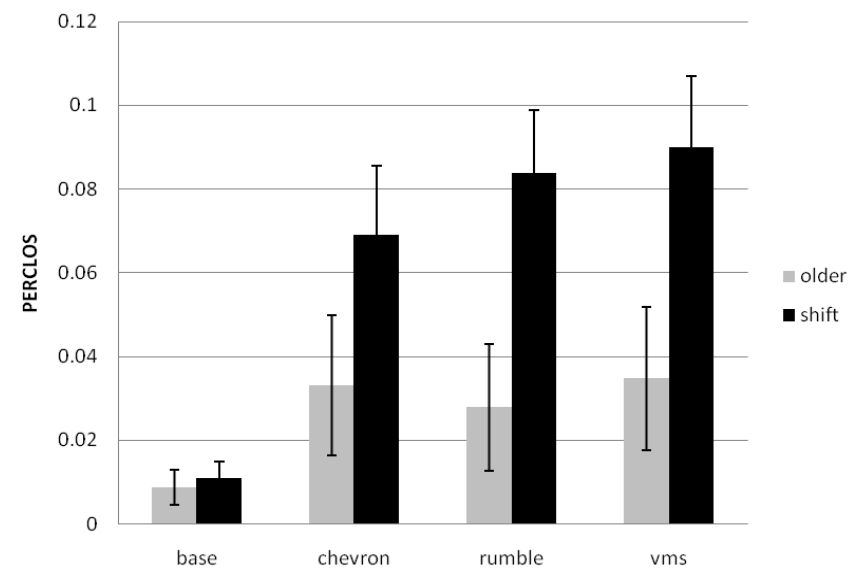

Figure 5. PERCLOS in "before" region

There was also a highly significant effect of group, such that the old group across their four drives showed significantly less eye-closure overall than the shift group, $F(1,32)=99.7, p<.00001$. There was also a significant interaction of drive and group, $F(3,93)=3.151, p=.029$. The interaction showed the increase in PERCLOS from baseline to treatment is significantly higher for the shift group than for the older group. This is in line with expectation since the shift group undertook their treatment drives after no sleep, whereas the older group only post lunch. PERCLOS appeared to differentiate well between the expected fatigue levels of both groups, giving confidence in its use as a dependent measure in the following analysis.

For each driver group, three further single-factor ANOVAs were undertaken for each treatment across three sections (before, treatment and after). Results are shown in Figure 6.
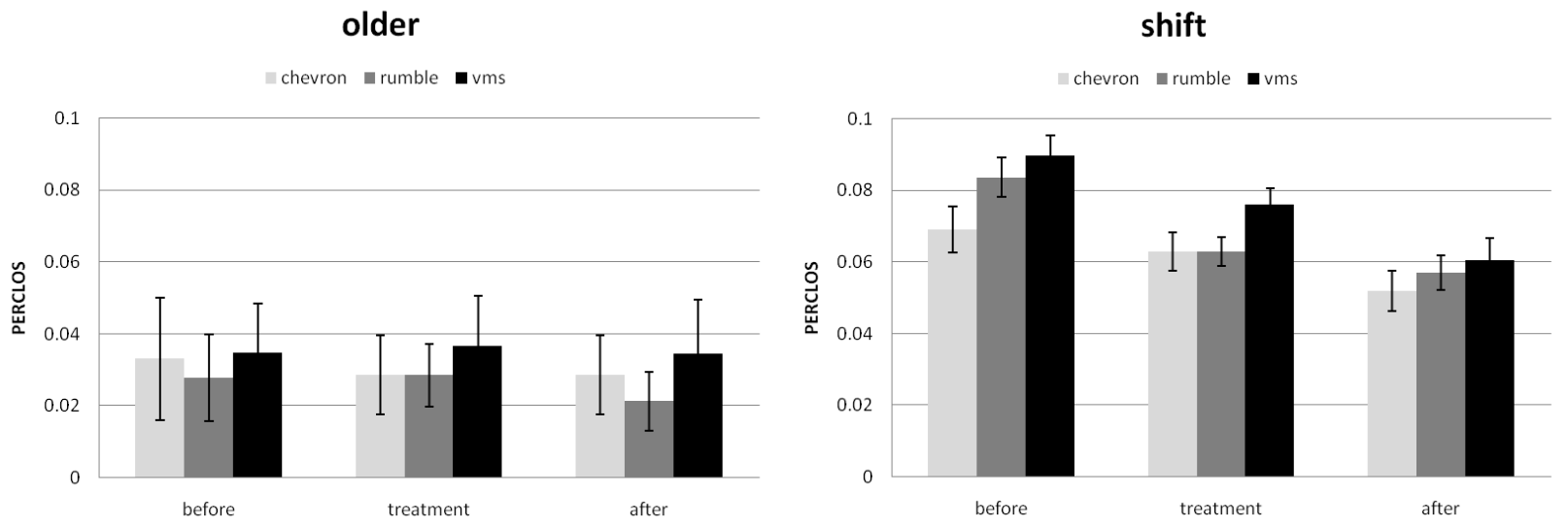

Figure 6. effect of each treatment on PERCLOS in the before, treatment and after regions

For the older group, there was no significant effect in a reduction in PERCLOS during or following any of the three treatments, however, a non-significant trend was observed for the rumble strips $(\mathrm{F}(2,31)=2.243, \mathrm{p}=.124)$. Given the inherent variability of psychophysiological data and the small sample size of the group, this result should not be immediately discarded. For the shift-worker group, there are similar small trends showing a marginal reduction in PERCLOS following each treatment: chevron, $\mathrm{F}(2,31)=2.350, \mathrm{p}=.113$; rumble, $\mathrm{F}(2,31)=2.180, \mathrm{p}=.15$; VMS, $F(2,30)=.3 .79, \mathrm{p}=.034$. 
High frequency component of steering

Besides PERLCOS, a two-factor ANOVA of drive and group was undertaken, comparing the high frequency component of steering in the "before" region and results are shown in Figure 7.

There was a main effect of drive, $\mathrm{F}(3,93)=3.637, \mathrm{p}=.016$. Pairwise comparisons show that this effect is between the baseline drive and each of the 'fatigued' treatment drives. Drivers' steering performance became more erratic (showing significantly higher high frequency component) from their baseline drive to their treatment drives, adding confidence in the measure at discriminating between levels of fatigue.

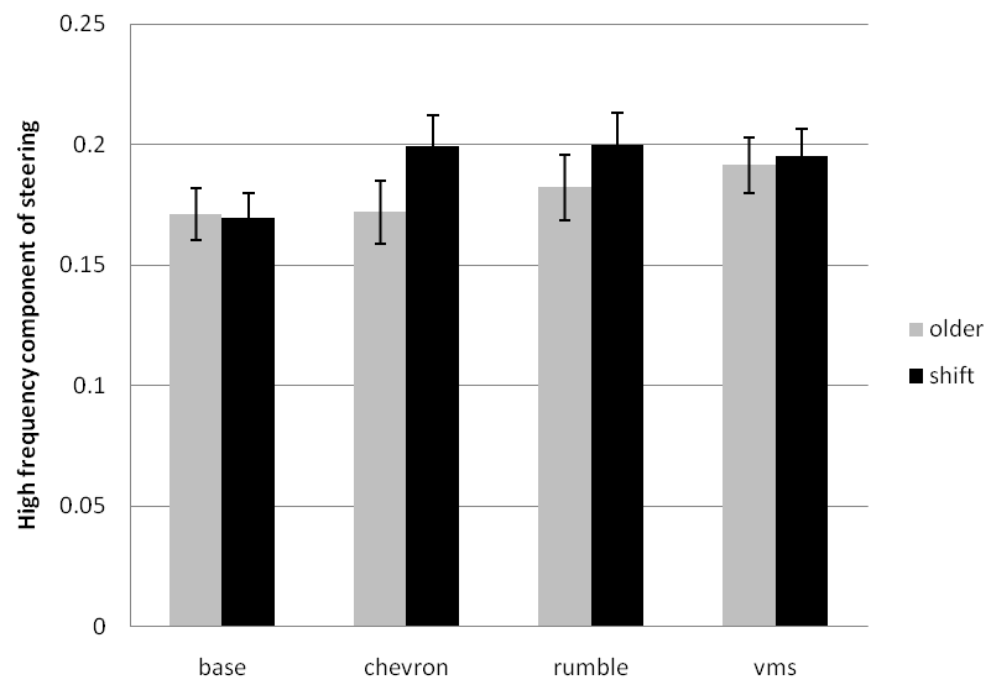

Figure 7. High frequency component of steering in the before region

For each driver group, three further single-factor ANOVAs were undertaken for each treatment across three sections (before, treatment and after). Results are shown in Figure 8.
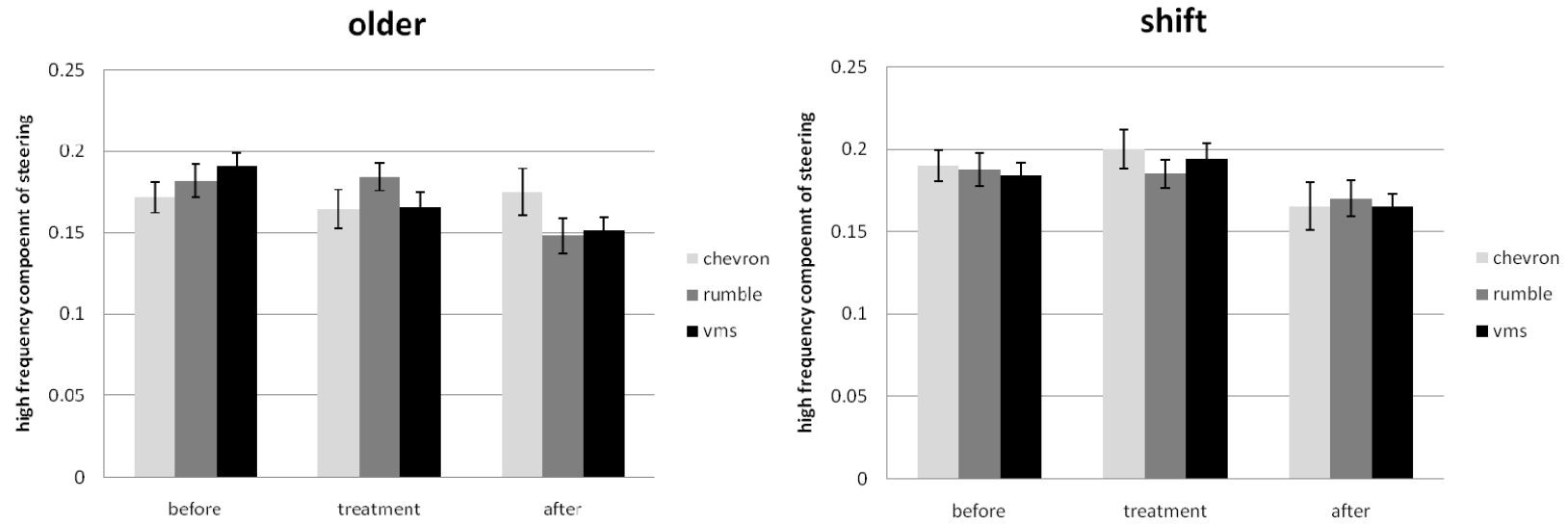

Figure 8. Effect of each treatment on high freq. steer in the before, treatment and after regions

For the older driver group, there was a significant improvement in steering performance following both the rumble treatment, $\mathrm{F}(2,30)=10.567, \mathrm{p}<.0001$; and the VMS treatment, $\mathrm{F}(2,30)=.8 .068, \mathrm{p}=.002$. The chevron treatment appeared to have little effect on this group.

For the shift-worker group, all three treatments resulted in a significant improvement in steering performance: chevron, $\mathrm{F}(2,30)=4.63$, $\mathrm{p}=.018$; rumble, $\mathrm{F}(2,30)=3.637$, $\mathrm{p}=.038$; vms, $\mathrm{F}(2,30)=3.412, \mathrm{p}=.046$. 


\section{CONCLUSIONS}

PERCLOS proved to be a very powerful dependent variable in discriminating level of fatigue between driving sessions. By comparing the before regions, PERCLOS was consistently and significantly higher in the non-fatigued baseline drive compared to other three fatigued treatment drives. Furthermore, it was able to discriminate levels of fatigue between groups, with the postlunch dip older group demonstrating much lower levels of PERCLOS than the sleep-deprived shift-workers.

Weak trends in the PERCLOS data suggested a small positive effect of all three treatments for shift workers: eye-closure was reduced in the $3 \mathrm{~km}$ region following a treatment compared a similar region before the treatment. The older group appeared to benefit from only from rumble treatment. Whilst acknowledging that the ANOVA never approached the 5\% level of confidence, it should be noted that there was a relatively high inter-subject variability in PERCLOS due to its psychophysiological nature as a measure. With such a small sample size, these small trends could not be ignored.

High frequency component of steering was also able to discriminate level of fatigue between driving sessions, showing steering to be significantly more erratic in the before region of the non-fatigued baseline drive compared to the same area of the three fatigued treatment drives. All treatments, with the exception of the chevrons for the older group, had a significant effect to improve steering performance pre-treatment compared to post-treatment.

Hence, it would appear that there is some evidence of an alerting effect on drivers experiencing all three of the treatments tested. However, the effect would appear to be relatively weak and potentially quite short-lived. That said, there may well be potential for any of the novel alerts to be deployed in a known fatigue-related accident blackspot, especially to reduce the otherwise monotonous driving environment.

Reyner and Horne (1998) believe that fatigue-related accidents are preceded by a self-awareness of sleepiness long before drivers reach the stage of fighting sleep. Whilst, the engineering treatments tested in this study have the potential for a very localised and global solution to a known fatigue problem, they do not combat fatigue except in their localised area of deployment. Furthermore, even if all were deployed in the field, the onus still remains with the individual to ensure that he/she is well aware of their own individual level of fatigue and to avoid driving when tired.

\section{REFERENCES}

Benoit, O. and Foret, J. (1988). Circadian regulation of the sleep-wake cycle. Clinical Neurophysiology, 18, pp. 403-31.

Dinges, D.F. (1995). An overview of sleepiness and accidents. Jrnl. Sleep Research, 4, pp. 4-14.

Horne, J.A. and Reyner, L.A. (1995). Sleep related vehicle accidents. British Medical Journal, 310 , pp. 565-567. 
Johns, M. W. (1991). A new method for measuring daytime sleepiness: The Epworth Sleepiness Scale. Sleep, 14, pp. 540-545.

Khardi, S. and Vallet, M. (1994). Drivers vigilance, analysis of differences in vigilance states assessments by physiological and mechanical indicators. Conference Proceedings 'Telematics for transport', Paris, pp. 1991-1998.

MacDonald, W.A. and Hoffman, E.R. (1980). Review of relationships between steering wheel reversal rate and driving task demand. Human Factors, 22, pp. 733-739.

McCartt, A.T., Ribner, S.A., Pack, A.I. and Hammer, M.C., (1996). The scope and nature of the drowsy driving problem in the New York state. Accident Analysis and Prevention, 28, pp. 511-517.

Mahoney, R.J., Porter, R.J. and Donnell, D.L. (2003). Evaluation of centerline rumble strips on lateral vehicle placement and speed on two-lane highways (No. FHWA-PA-2002-034-97-04 (111)). Harrisburg: Pennsylvania Department of Transportation.

Maycock, G. (1997). Sleepiness and driving: the experience of U.K. car drivers. Accident Analysis and Prevention, 29, pp. 453-462.

Pack A.I., Pack A.M., Rodgman, E., Cucchiara, A., Dinges, D.F. and Schwab, C.W. (1995). Characteristics of crashes attributed to the driver having fallen asleep. Accident Analysis and Prevention, 27, pp. 769-75.

Räsänen, M. (2005). Effects of a rumble strip barrier line on lane keeping in a curve. Accident Analysis and Prevention, 37, pp. 575-581.

Reyner, L.A. and Horne, J.A. (1998). Evaluation "in-car" countermeasures to sleepiness: cold air and radio. Sleep, 21, pp. 46-51.

Sagberg, F (1999). Road accidents caused by drivers falling asleep. Accident Analysis and Prevention, 31, pp. 639-49.

Wierwille, W.W., Ellsworth, L.A., Wreggit, S.S., Fairbanks, R.J., and Kirn, C.L. (1994). Research on Vehicle-Based Driver Status/Performance Monitoring: Development, Validation, And Refinement of Algorithms for Detection of Driver Drowsiness. Final Report. (DOT HS 808 247). Washington, D.C.: National Highway Traffic Safety Administration. 